\title{
MATERIAL BALANCE FOR STEPWISE EXTRACTION OF FRESHWATER ALGAE BIOMASS WITH HEAVY METAL SEQUESTRATION
}

\author{
BILANS MATERIAŁOWY STOPNIOWEJ EKSTRAKCJI BIOMASY GLONÓW \\ SŁODKOWODNYCH Z ODDZIELENIEM METALI CIĘŻKICH
}

\begin{abstract}
During our studies concerning the isolation of sulfated polysaccharides (SPs) from freshwater algae species widespread in Poland, an improved overall extraction methodology has been developed. This new, multi-step procedure allows for obtainment of several fractions that could find use in cosmetic and food industries, with the final one containing the valuable SPs, important both from economic and scientific perspective. Moreover, the process allows for easy use of typical chelating agents to remove harmful heavy metal ions without important losses in natural compounds of interest. Furthermore, a material balance has been established for said process, allowing for its easier implementation on bigger scales, and highlighting the areas which could still be improved to positively affect the final time-cost ratio of the methodology. Combined with previously published information concerning the detailed composition of obtained fractions, we aim to provide a robust and informative outlook on the potential of native freshwater algae species as cheap, raw and easily purifiable resource, usable in a number of important industries. According to the mass balance, nearly $5 \%$ of dry mass of Cladophora glomerata is extractable with ethanol and this fraction consists mostly of fatty acids, phenolics and pigments. Another $5 \%$ of mass can be isolated as pure SPs from aqueous fraction. Additionally, calcium from natural incrustations on the surface of $C$. glomerata amounts to $17 \%$ of dry material weight and can be reclaimed from acidic wash by simple precipitation; such calcium salts have garnered significant interest as nutritional supplements.
\end{abstract}

Keywords: algae, extraction, fatty acids, antioxidants, sulfated polysaccharides, phenolic compounds, Cladophora glomerata

\section{Introduction}

Algal biomass is becoming ever more popular as a raw resource: both as an important source of varied nutrients, as well as more specialized - bioactive - compounds. As feedstock, it provides a balanced and rich diet of fatty acids, vitamins, fiber and more easily digestible sugars [1-3]. Micronized dry algae have become a popular food supplement and even a "superfood" in their own right [3]. Agar is now arguably more popular than gelatin with varied uses in the laboratory, and because of the trend to embrace more plant-derived substances. On the other hand, multi-component algal extracts have found a solid footing as

\footnotetext{
${ }^{1}$ Faculty of Chemistry, Adam Mickiewicz University in Poznań, ul. Uniwersytetu Poznańskiego 8, 61-614 Poznań, Poland

"Corresponding author: lukasz.tabisz@amu.edu.pl
} 
cosmetic ingredients [4] - and one cannot forget that different species of algae, with different distribution of pigments, are a convenient source of natural alternatives to synthetic colorings [3].

Polish reservoirs of algal biomass lie in the lakes and rivers, not in the sea - but those are still considerable [5]. Often perceived as a nuisance or an outright danger to biodiversity (when in bloom), naturally occurring algal species like Cladophora glomerata or Ulva flexuosa find little to no use in the abovementioned sectors of industry. This is chiefly due to a persisting deficit of studies concerning freshwater species - both in domestic literature and international. Although a slow process, recent papers have revealed that our native species of algae are just as rich in bioactive compounds as those found abroad or in the marine environment [6]. It seems therefore unavoidable that industrial applications will soon follow - after the completion of thorough scientific examinations.

Among the nonpolar compounds of interest, algae are rich in fatty acids and carotenoids [7], while the content of other pigments, e.g. chlorophylls, depends mainly on the species. They are also a rich source of polyphenolic antioxidants and other phenolic compounds $[8,9]$, which they employ in allelopathic interactions with their environment [10]. Polar compounds present in algal biomass consist of amino acids, peptides, peptidoglycans and polysugars - among which sulfated polysugars (SPs) are the most sought-after group, because of their heightened bioactivity compared to other carbohydrates [11]. However, the presence of ionic polymers in cell walls of algae are one of the reasons behind the possible bioaccumulation of heavy metal ions from their aqueous environment $[12,13]$. In fact, both live algae and algal biomass have been used as natural biosorbents for just that specific purpose in water remediation $[13,14]$. Those heavy metal pollutants must be removed from extracts used in food or cosmetic industries. On the other hand, incrustations, composed mainly of calcium carbonate [15], form on the surface of algal thalli and can amount to a significant portion of the material mass - severely reducing the yield of any extraction, and possibly contaminating the aqueous fraction.

With this in mind, we set out to establish a preliminary material balance for stepwise, small-scale extraction of the biomass of freshwater Cladophora glomerata. The aim was to provide a semi-economic framework that could be furnished using previously published data concerning particular compounds (and groups thereof) that can be isolated from such biological material using different solvent systems. This is also described in following sections. The multi-step approach presented in this work allows for isolation of different potentially valuable fractions (including the sulfated polysaccharide fraction [16]), while simultaneously removing heavy metal ions - a common algal biomass contaminant in a selective manner, without sacrificing any important compounds in the process.

\section{Materials and methods}

\section{Algal biomass}

The biomass of Cladophora glomerata was gathered from Oporzyn Lake in the Wielkopolska region in summer 2016. It was dried and milled on-site to prevent decomposition. Since then, regular extractions have proved that - apart from the most volatile compounds, which were not a part of our studies - there is negligible alteration in the chemical composition of the material during storage (dark container, limited air access, ambient temperature). 


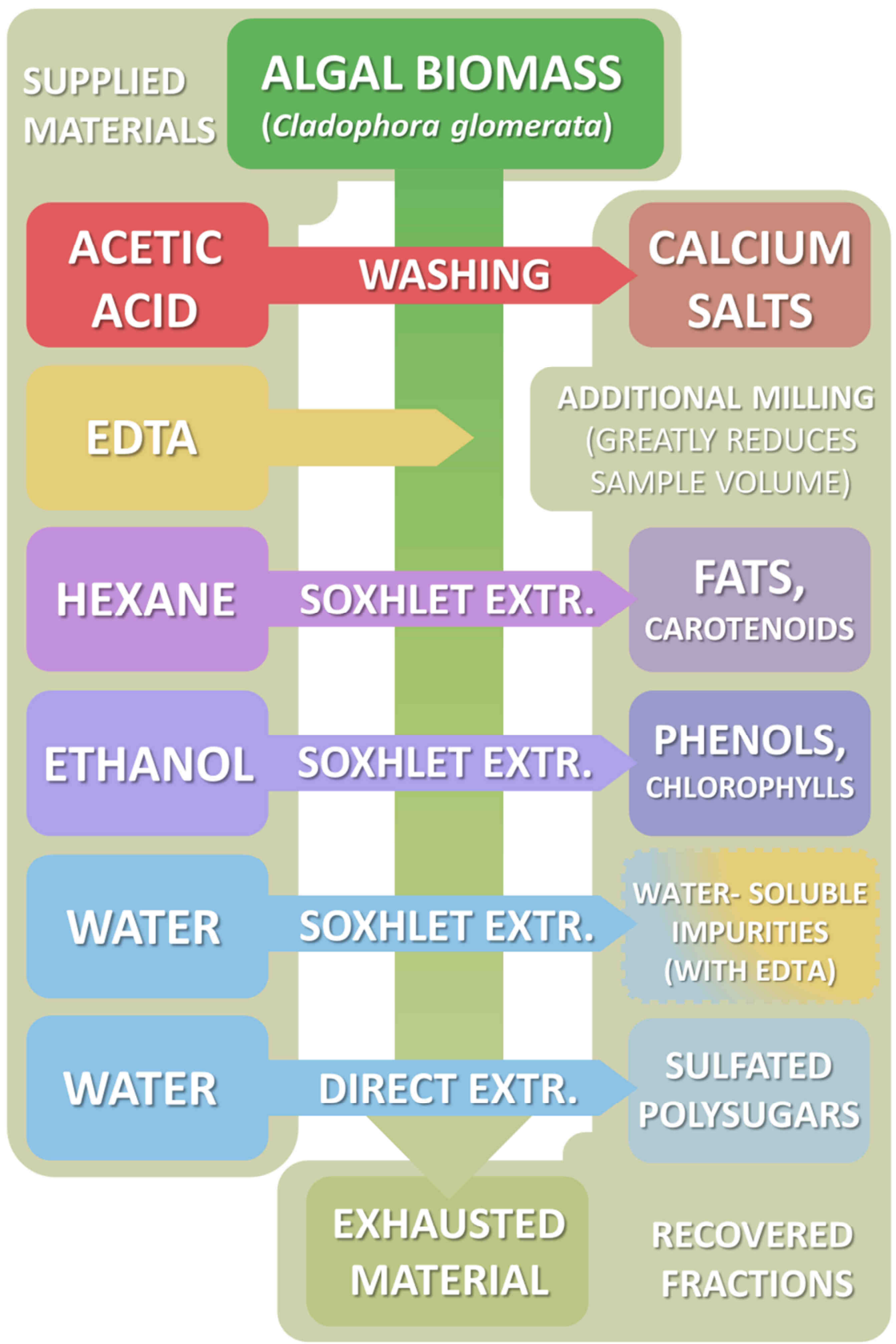

Fig. 1. Methodology scheme for stepwise extraction of Cladophora glomerata. EDTA stands for ethylenediaminetetraacetic acid (as disodium salt). Details are given in Materials and Methods 


\section{Reagents and analytical instruments}

Solvents and reagents were purchased either from Merck or POCH (Avantor) and were of analytical or higher grade; they were used without additional purification. All infrared spectra were recorded in KBr tablets using Bruker IFS 66v/S FT-IR spectrometer.

\section{Novelty of the extraction methodology}

Devised step-wise approach allows for semi-selective isolation of most of the important compounds available in algal biomass, starting from least to most polar. However, to facilitate further extraction procedures and reclaim the calcium from incrustations which are present on the surface of $C$. glomerata, an acidic wash was established as the first step. The methodology is further summarized in Figure 1.

The material for the thimble used with the Soxhlet apparatus is an issue of crucial importance, although often overlooked. The authors of the manuscript have devoted a significant effort to test different easily available materials for use with the developed extraction methodology. Neither paper, hard cellulose (commercial thimbles) nor regular cloth offered acceptable results; those were obtained only with sterile bandage cloth, easily available at pharmacies (particularly, the LEINA-WERKE brand was used in this study). The material should be carefully sewn in the desired shape, not stapled. Care should be taken to prepare a somewhat smaller container than the size of Soxhlet chamber (width), as the material will stretch when the biomass swells and possibly hinder solvent penetration (and, later on, removal of the thimble, which can tear under stress).

\section{Detailed extraction procedure}

Acetic acid wash. Dry biomass of freshwater Cladophora glomerata (100 g) is weighted and placed in a wide, $2 \mathrm{dm}^{3}$ crystallizing dish. A solution of acetic acid $(54 \mathrm{~g})$ in water $\left(700 \mathrm{~cm}^{3}\right)$ is slowly poured over the material. A glass rod is used to slowly stir the contents, and immediately a vigorous reaction commences; the mixture will continue to rise and care must be taken to not let it spill out of the container. After about 5 minutes the effervescence starts to fade, and the mixture can be stirred only occasionally, until no more gaseous products are given off (no more than 30 minutes). The pulp is transferred into a piece of cloth (the same material as that used for the thimble works well), sufficiently big to allow for manual squeezing to remove the absorbed liquid. The obtained paste is rinsed with cold, deionized water $\left(20-30 \mathrm{~cm}^{3}\right)$ and squeezed again; this step is repeated thrice. The combined aqueous phase can be evaporated and the residue dried to yield quantitatively the calcium acetate fraction (68.97 g). Alternatively, other poorly soluble calcium salt can be precipitated directly from this solution and the liberated acetic acid distilled for reuse. The decalcified mass is then dried at $65^{\circ} \mathrm{C}$ for at least 15 hours.

EDTA addition and milling. Disodium salt of ethylenediaminetetraacetic acid (dihydrate, $6.67 \mathrm{~g}$ ) is weighted and mixed with dried, decalcified biomass, then thoroughly grinded (an electric coffee grinder works very well for smaller portions). The processed material should be fully pulverized, homogenous, with an appearance of a pale-green powder.

Hexane extraction. The cloth thimble (see Novelty of the extraction methodology) with pulverized, decalcified mass is placed in a Soxhlet apparatus $\left(250 \mathrm{~cm}^{3}\right.$ volume $)$, equipped with a reflux condenser. A round-bottom flask (1-2 $\mathrm{dm}^{3}$ volume) with $400 \mathrm{~cm}^{3}$ of hexane and a boiling chip is connected, and the side tube for solvent vapors is protected with 
aluminum foil (to reduce the need for excessive heating). It is advisable to leave a few millimeters of space between the heating mantle and the walls of glassware, and also not to cover the flask with the mantle above the level of liquid. The extraction is then carried out for 24 hours, after which time the extract is filtered hot through a filter paper into a weighted round-bottom flask and evaporated under reduced pressure to yield a small, fatty acid-dominated fraction (dark-green wax, $1.26 \mathrm{~g}$ ). The flask can be changed to a much smaller one after the volume of liquid has been reduced to about $50 \mathrm{~cm}^{3}$. The thimble is removed from the Soxhlet apparatus and left either in an oven $\left(65{ }^{\circ} \mathrm{C}, 4\right.$ hours $)$ or under a working fume hood ( 24 hours, ambient temperature) to remove the remaining solvent.

Ethanol extraction. The process is carried out nearly identically to the last step, only with the solvent changed. After a 24 hour extraction the liquid is filtered hot through a filter paper into a weighted round-bottom flask and evaporated under reduced pressure to yield a moderate fraction of phenolics and pigments (dark-green powder, $3.60 \mathrm{~g}$ ). The flask can be changed to a much smaller one after the volume of liquid has been reduced to about $50 \mathrm{~cm}^{3}$. The thimble is removed from the Soxhlet apparatus and left either in an oven $\left(65{ }^{\circ} \mathrm{C}, 8\right.$ hours) or under a fume hood ( 24 hours, ambient temperature) to remove the remaining solvent.

Water extraction (Soxhlet and direct). The process is carried out similarly to previous steps, with change of solvent and additional protection of the $2 \mathrm{dm}^{3}$ round-bottom flask with aluminum foil (the flask should be covered entirely; the large volume of the container is necessary due to the properties of the extract, which becomes increasingly viscous and prone to foaming as time passes). After a 24 hour extraction the liquid is filtered hot through a thick layer of cotton into a weighted volumetric flask and evaporated under reduced pressure and then lyophilized to yield the EDTA fraction with a minor amount of protein impurities and other salts (dark-brown powder, $7.03 \mathrm{~g}$ ). For most non-research purposes this fraction can be discarded immediately after extraction. The contents of the thimble are then removed into a $500 \mathrm{~cm}^{3}$ glass bottle equipped with a large magnetic stirrer and the thimble itself washed with $50 \mathrm{~cm}^{3}$ of hot water thrice. Additional $150 \mathrm{~cm}^{3}$ of water is added and the mixture brought to $85-90{ }^{\circ} \mathrm{C}$ with vigorous stirring. The bottle is closed, and the direct extraction proceeds for 24 hours again. Afterwards the mixture is divided as needed and centrifuged until no particulate matter is seen in the volume of water (the solution will remain cloudy, however) and filtered (preferably still warm or even hot) through cotton to a round-bottom flask with a volume of at least $1 \mathrm{dm}^{3}$. The water is evaporated under reduced pressure until $100 \mathrm{~cm}^{3}$ remains and $900 \mathrm{~cm}^{3}$ of $96 \%$ ethanol is added (with shaking) while the extract is still warm. The sulfated polysugars are left to precipitate for $48-72$ hours in a refrigerator $\left(4{ }^{\circ} \mathrm{C}\right)$. The solution is then again centrifuged until a solid, beige, spongy cake deposits on the bottom of the bottles and the supernatant can be easily discarded. The solids are transferred into a large Petri dish and dried in an oven $\left(65{ }^{\circ} \mathrm{C}, 15-24\right.$ hours), preferably with additional grinding (mortar and pestle are sufficient at this point) near the end. Sulfated polysugars are obtained as an off-white powder $(5.03 \mathrm{~g})$.

\section{Results and discussion}

\section{Material balance determination}

The full extraction methodology was performed twice, and additionally the process was scaled up from original 30 grams of dried algal biomass to 100 grams. The results were 
consistent between all runs. Additional modifications of the procedure were performed separately to test other hypotheses or add data to the material balance (Table 1) and are discussed in detail in the following sections.

Table 1

Material balance for stepwise extraction of Cladophora glomerata calculated for $100 \mathrm{~g}$ of dry material

\begin{tabular}{|c|c|c|c|c|c|c|}
\hline \multirow[b]{2}{*}{ Step } & \multicolumn{3}{|c|}{ Acetic acid wash } & \multicolumn{3}{|c|}{ Citric acid wash } \\
\hline & $\begin{array}{c}\text { Mass added } \\
{[\mathrm{g}]}\end{array}$ & $\begin{array}{c}\text { Mass } \\
\text { retrieved }[\mathrm{g}]\end{array}$ & Notes & $\begin{array}{c}\text { Mass added } \\
{[\mathrm{g}]}\end{array}$ & $\begin{array}{c}\text { Mass } \\
\text { retrieved }[\mathrm{g}]\end{array}$ & Notes \\
\hline $\begin{array}{l}\text { Weighting of } \\
\text { algal biomass }\end{array}$ & 100.00 & - & - & 100.00 & - & - \\
\hline Acid wash & 54.00 & 68.97 & - & 157.50 & 169.23 & $\begin{array}{c}\text { excess acid } \\
\text { used }^{\text {b }}\end{array}$ \\
\hline EDTA addition $^{\mathrm{a}}$ & 6.67 & - & - & 6.67 & - & - \\
\hline $\begin{array}{c}\text { Hexane } \\
\text { extraction }\end{array}$ & - & 1.26 & \multirow{2}{*}{$\begin{array}{c}\text { Without } \\
\text { hexane } \\
\text { extraction: } \\
4.87 \mathrm{~g}\end{array}$} & - & 1.46 & - \\
\hline $\begin{array}{c}\text { Ethanol } \\
\text { extraction }\end{array}$ & - & 3.60 & & - & 14.57 & \multirow{3}{*}{$\begin{array}{l}\text { Mostly citric } \\
\text { acid and } \\
\text { calcium citrate }\end{array}$} \\
\hline $\begin{array}{l}\text { Water extraction } \\
\text { (Soxhlet) }\end{array}$ & - & 7.03 & $\begin{array}{c}\text { Non-EDTA } \\
\text { mass: } \\
\sim 0.3 \mathrm{~g}\end{array}$ & - & 16.53 & \\
\hline $\begin{array}{c}\text { Water extraction } \\
\text { (direct) }\end{array}$ & - & 5.03 & - & - & 1.80 & \\
\hline \multicolumn{7}{|c|}{ Other mass factors } \\
\hline $\begin{array}{c}\text { Exhausted } \\
\text { material }\end{array}$ & - & 34.43 & - & - & 33.00 & - \\
\hline $\begin{array}{c}\text { Carbon dioxide } \\
\text { loss }\end{array}$ & - & $19.18^{c}$ & $\begin{array}{c}\text { From incrusts } \\
\text { (carbonate) }\end{array}$ & - & $19.18^{\mathrm{c}}$ & $\begin{array}{c}\text { From incrusts } \\
\text { (carbonate) }\end{array}$ \\
\hline Water loss & - & $8.50^{c}$ & $\begin{array}{c}\text { Carbonate and } \\
\text { EDTA } \\
\text { dihydrate }\end{array}$ & - & $21.99^{c}$ & $\begin{array}{c}\text { Carbonate, } \\
\text { EDTA and } \\
\text { citric acid } \\
\text { hydrates }\end{array}$ \\
\hline Other & - & $1.40^{\mathrm{c}}$ & $\begin{array}{c}\text { Excess of } \\
\text { acetic acid } \\
\text { (calculated) }\end{array}$ & $5.11^{\mathrm{c}}$ & - & $\begin{array}{c}\text { Hydration of } \\
\text { calcium citrate } \\
{[17]}\end{array}$ \\
\hline Total & 160.67 & 149.40 & & 269.28 & 277.76 & \\
\hline Balance & \multicolumn{3}{|c|}{-11.27} & \multicolumn{3}{|c|}{+8.48} \\
\hline
\end{tabular}

a Disodium salt of EDTA (dihydrate), amount calculated to correspond with previously [16] determined amount of sulfated polysaccharides and rounded up to $2 \mathrm{~g}$ per one $30 \mathrm{~g}$ extraction run. ${ }^{\mathrm{b}}$ Calcium citrate is better soluble in excess citric acid. ${ }^{c}$ Values calculated based on chemical composition of used reagents and other parts of material balance. Masses of used solvents were omitted in all cases; solvents can be recovered through low-pressure distillation and reused. All values were calculated for $100 \mathrm{~g}$ of dry algal biomass as starting material.

\section{Removal of calcium incrustations}

Water is the main component of fresh algal biomass, with the first drying process removing as much as $90 \%$ of its initial weight. However, it came somewhat as a surprise that the remaining material consisted of over $40 \%$ calcium carbonate. Apart from a hindering "dead weight" effect on following extractions, brief washing with aqueous acidic acid followed by drying and milling drastically changes the material bulk density, from 160 to $480 \mathrm{~kg} \cdot \mathrm{m}^{-3}$ (Fig. 2). This allowed for subsequent extraction of $50 \mathrm{~g}$ instead of planned $20 \mathrm{~g}$ using the same setup (a $250 \mathrm{~cm}^{3}$ Soxhlet apparatus). Despite the fact that the mass of ethanol extract decreased between runs with raw and decalcified material (although insignificantly, from $4.98 \mathrm{~g}$ per $100 \mathrm{~g}$ of dry mass to $4.87 \mathrm{~g}$ per $100 \mathrm{~g}$ ), the speed of 
extraction was markedly faster after removal of incrusts. The process could, therefore, be further optimized by shortening the time of each step; that aspect was however beyond the scope of presented work. Apart from those advantages, calcium carbonate is a very cheap material, recovery of which can be hard to argue from an economic standpoint. However, calcium salt supplements [18] have become very popular in recent years, with "biogenic" or "natural" calcium sources marketed as superior alternatives to mined (rock) lime or limestone. Precipitation from acetate solution or washing with different acid (e.g. citric acid - see following section) can yield such material as an additional, viable first fraction of the proposed extraction methodology. As an additional benefit, the characteristic, somewhat fish-like smell of algal biomass is lost during the wash, replaced by a more agreeable, herbal aroma after drying; this is despite the fact that according to recent literature - amines and pyridines constitute only a minor fraction of their odorants [19].
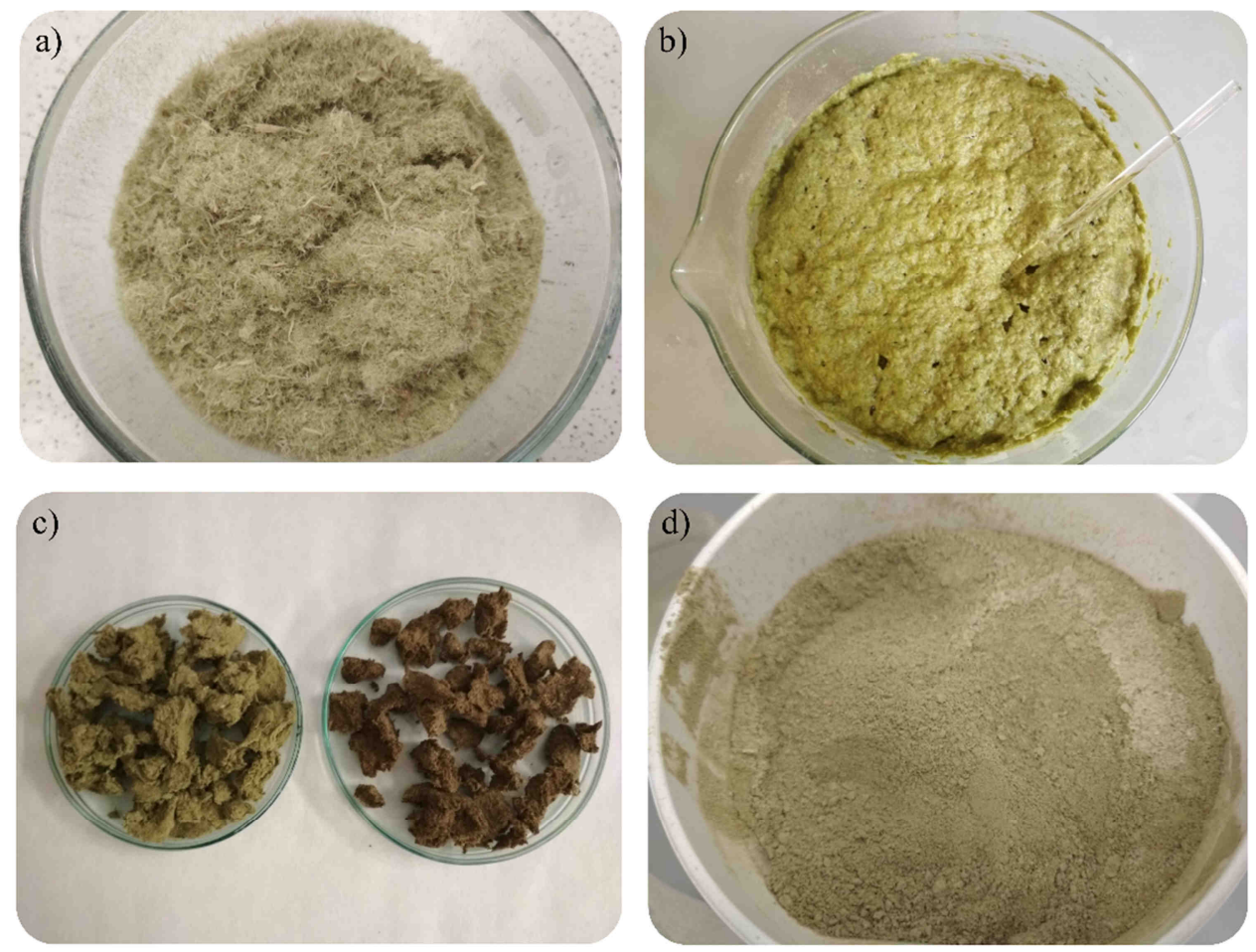

Fig. 2. Decalcification procedure for removal of calcium carbonate incrustations from Cladophora glomerata; a) dry algal biomass before the acid wash, b) during acetic acid wash, c) comparison between material treated with acetic (left) and citric acid (right), after drying, with evident degradation of plant pigments in the latter case, d) pulverized, decalcified biomass after acetic acid wash and drying, already ground together with disodium EDTA

\section{Citric acid variation}

Acetic acid has many advantages for calcium carbonate removal: it forms soluble salts with calcium, is a fairly weak acid, non-toxic, and its excess can be easily removed by 
evaporation. However, following the determination of high incrust content we decided to repeat the full procedure using citric acid - as it retains most of the aforementioned advantages (save for volatility), but calcium citrate is an already well-established nutritional supplement [18]. Despite the fact that the majority of citric acid/calcium citrate was indeed removed in the first step, the damage to bioactive compounds in the material even with brief washing was evident (Fig. 2c). Even worse, both citric acid and its salts were retained in substantial amounts and dominated the FT-IR spectra of every fraction other than that obtained from hexane; even the second water extract was contaminated (Table 1). Meanwhile, acetic acid/acetate was wholly accounted for after the first, washing step. Although none of those salts and carboxylic acids are toxic and would not prove harmful in extracts, this particular alteration of methodology cannot be recommended. It seems therefore much more efficient to precipitate calcium citrate (or any other preferred, less soluble salt) from the acetate wash; the spent acetic acid could even be distilled and reused, if a minimum-waste approach is aimed for.

\section{Omission of hexane extraction step}

Previous studies have concluded that dry freshwater macroalgae are rich in free fatty acids, but their overall fat content is not very high [20]. That was again proved by our examinations. As the hexane extract amounted only to $1.26 \%$ of dry mass, we hypothesized that even with low solubilities of fats and similar compounds in ethanol, Soxhlet extraction would allow for their isolation - along with other important, more polar compounds. This was indeed the case, as proved by both the mass balance and FT-IR spectra: all the bands previously present in hexane extract were now easily seen in the ethanolic fraction (Fig. 3). For most non-research purposes, therefore, omitting the hexane extraction should be acceptable, and even preferable to the full methodology.

\section{Addition of EDTA and isolation of sulfated polysaccharides (aqueous fractions)}

In our preliminary studies we have found that the mass obtained after evaporation of water extract obtained with a Soxhlet apparatus was a very modest $0.97 \mathrm{~g}$ per $100 \mathrm{~g}$ of dry biomass. That obviously meant that the bulk of sulfated polysaccharide (SP) fraction was left inside the thimble, as that fraction should amount to 5-10\% of dry mass [16]. The extract, however, was quite viscous, brown and showed a protein-rich FT-IR spectrum, with some bands that could be ascribed to sulfates and other salts - probably inorganic matter or small sulfated sugar molecules cleaved from the polysaccharide chain: all notable contaminants of SPs isolated by conventional means. Effectively, Soxhlet extraction has supplanted the role of membrane dialysis, with SP isolated afterwards being already free of colored compounds, most peptides and salts. The importance of this step in our methodology was further augmented by application of EDTA as a chelator: both to leech calcium from SP structure (which allows for their easier extraction from the cell wall) and to simultaneously capture heavy metal contaminants that could be present in the material [21]. The mass balance and FT-IR spectra have again shown that all of the chelator (even at high, $>10 \% \mathrm{w} / \mathrm{w}$ proportion to decalcified biomass) was successfully extracted with the first aqueous fraction, and none could be found in the ethanolic extract. At such concentrations, it can be assumed that even fairly heavy metal-contaminated algal biomass could be rendered usable in cosmetic or even food industries - at just the cost of a suitable chelating agent, and without sacrificing any vital compounds (fatty acids, phenolics, pigments, sulfated polysugars). 


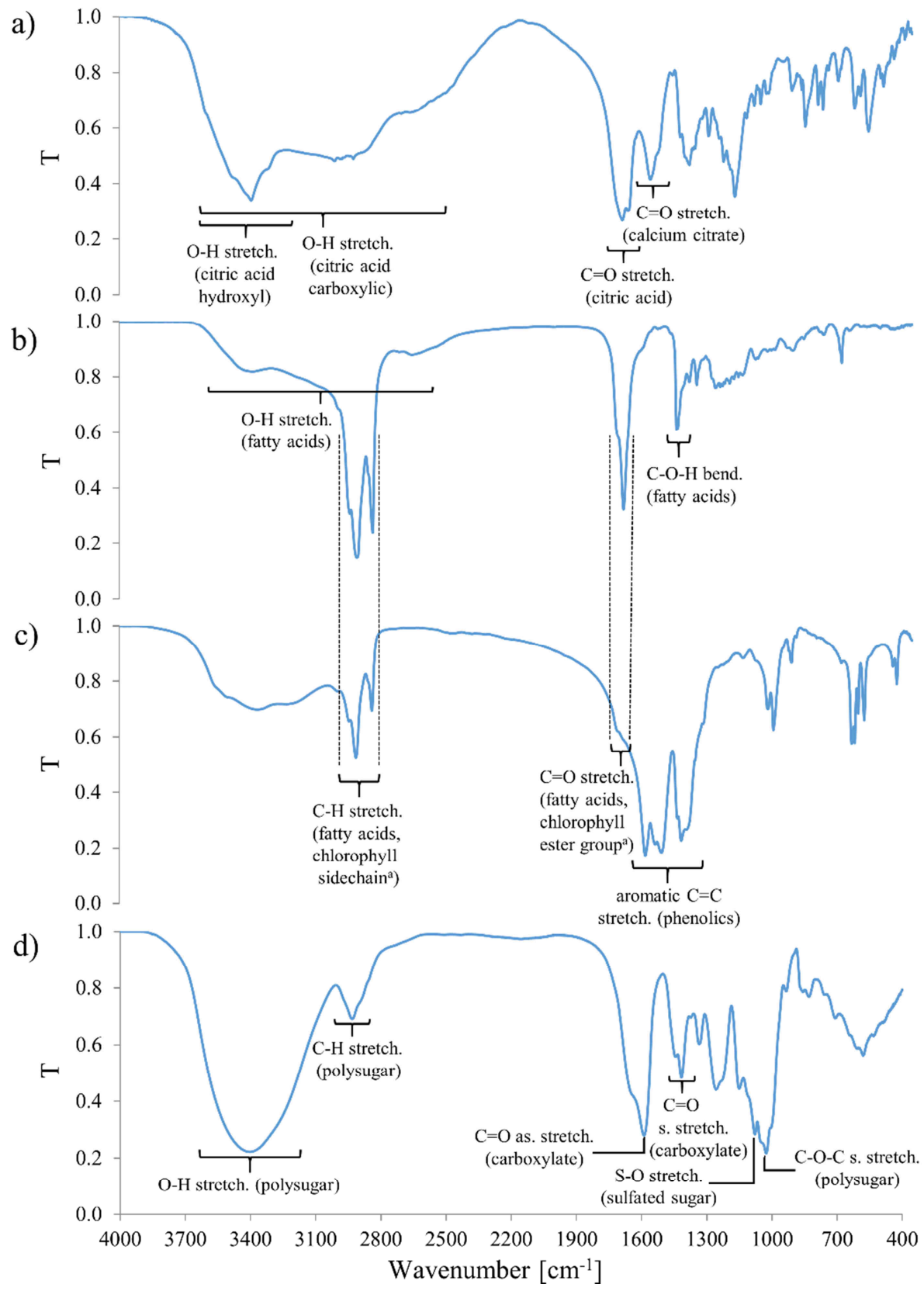

Fig. 3. FT-IR spectra (in $\mathrm{KBr}$ ) of different fractions isolated from C. glomerata; a) calcium citrate/citric acid mixture obtained after the deincrustation step; b) hexane fraction showing a spectrum nearly identical to a pure fatty acid; c) ethanol fraction obtained after skipping the hexane extraction, showing a large amount of phenolics together with absorption bands indicative of successfully isolated fatty acids (dashed lines show exactly the same position of bands on both spectra), d) pure polysaccharidic fraction, with bands from both carboxylate and sulfate moieties present, ${ }^{\mathrm{a}}[22]$ 


\section{Mass balance irregularities}

The calculated mass balance revealed that with the more reliable version of methodology, utilizing acetic acid, $7 \%$ of mass introduced to the process could not be accounted for. Some mass deficits can be definitely ascribed to: (a) filtration, performed in between every step of the procedure, which removed cellulose fibers and particulate matter; and (b) loss of volatile compounds. The former is thought to be the main route of matter escape from the system, and should decrease with scaling up of the process. However, due to form and constituents of some apolar fractions, and their reluctance to release solvent traces, exhaustive low-pressure evaporation that was performed could theoretically pose a risk of compound vaporization (e.g. sublimation of phenolics). That risk can be reasonably mitigated only by restricting the extraction to safe solvents and limiting evaporation times. Minute amounts of bioethanol - for example - remaining in extracts should not interfere with their application in foodstuffs and cosmetics.

\section{Conclusions}

The devised stepwise extraction methodology and accompanying material balance presented in this study highlight some important factors concerning the usefulness of freshwater green algae species for food and cosmetic industries. The economy of the process is greatly increased by removal of calcium carbonate incrustations, which can amount to over $40 \%$ of dry algae mass. This abundant "natural calcium" fraction can be potentially reused as a nutritional supplement, e.g. in the form of citrate, by simple precipitation from acetic acid wash. The fatty acid-rich hexane fraction can be omitted, for most purposes, as we have proven that all of the relevant extractable matter is also isolated using ethanol (a very mild or even "green" solvent - one that can also be easily reused between extractions, following distillation under reduced pressure, and has already been cited as one of the best possible solvents for use in algal biomass extraction [23]) during the next $24 \mathrm{~h}$ step - therefore rendering that particular fraction arguably the most valuable in terms of compounds sought after in cosmetics and foodstuffs. Addition of disodium salt of EDTA after the acidic wash and a two-step water extraction result in a pure, decolorized and mineral-free sulfated polysaccharide fraction. Meanwhile the chelator - along with any possible heavy metal contaminants - is wholly accounted for in the first aqueous extract. As apart from EDTA it constitutes only a very minor $(0.3 \%)$ fraction of extractable material, containing mostly peptides and minerals, it can safely be discarded.

The developed methodology, supported by material balance, proves that freshwater algae species native to Poland, like Cladophora glomerata, are a viable source of bioactive compounds ( $\sim 10 \%$ of dry mass) and calcium ( $\sim 17 \%$ of dry mass) that could find use in the industry. Moreover, the potential hazard associated with heavy metal accumulation in algal biomass and resulting contamination of cosmetic or food products can be circumvented simultaneously - without the need to add steps or subtract valuable compounds from the extraction process. This can be a potential route to popularization of this natural raw material, which is cheap and easily available, and eventually remedy the persisting lack of infrastructure responsible for managing and utilization of freshwater algae widespread in Polish inland waters. 


\section{Acknowledgements}

This project was financed in the framework of grant 2014/13/B/NZ8/04690 ("Physicochemical and biological causes of ecological dominance of filamentous green algae in freshwater ecosystems") from the Polish National Science Centre in years 2015-2018.

\section{References}

[1] Khatoon N, Sengupta P, Homechaudhuri S, Pal R. Proc Zool Soc. 2010;63(2):109-14. DOI: 10.1007/s12595-010-0015-3.

[2] Stamey JA, Shepherd DM, De Veth MJ, Corl BA. J Dairy Sci. 2013;95(9):5269-75. DOI: 10.3168/jds.2012-5412.

[3] Kovač DJ, Simeunović JB, Babić OB, Mišan AČ, Milovanović IL. Food Feed Res. 2013;40(1):21-31. http://fins.uns.ac.rs/e-journal/uploads/Magazines/magazine_123/Algae-in-food-and-feed.pdf.

[4] Wang HMD, Chen CC, Huynh P, Chang JS. Bioresour Technol. 2015;184:355-62. DOI: 10.1016/j.biortech.2014.12.001.

[5] Pikosz M, Messyasz B. Oceanol Hydrobiol Studies. 2016;45(2):202-15. DOI: 10.1515/ohs-2016-0019.

[6] Messyasz B, Leska B, Fabrowska J, Pikosz M, Roj E, Cieslak A, et al. Open Chem. 2015;13(1):1108-18. DOI: 10.1515/chem-2015-0124.

[7] Christaki E, Bonos E, Giannenas I, Florou-Paneri P. J Sci Food Agricult. 2013;93(1):5-11. DOI: $10.1002 /$ jsfa.5902.

[8] López A, Rico M, Rivero A, de Tangil MS. Food Chem. 2011;125(3):1104-9. DOI: 10.1016/j.foodchem.2010.09.101.

[9] Soltani S, Saadatm S, Khavarinejad R, Nejadsattari T. Afr J Biotechnol. 2011;10(39):7684-9. DOI: 10.5897/AJB11.491.

[10] Fabrowska J, Messyasz B, Pankiewicz R, Wilińska P, Łęska B. Water Res. 2018;135:66-74. DOI: 10.1016/j.watres.2018.02.020.

[11] Costa LS, Fidelis GP, Cordeiro SL, Oliveira RM, Sabry DDA, Câmara RBG, et al. Biomed Pharmacother. 2010;64(1):21-8. DOI: 10.1016/j.biopha.2009.03.005.

[12] Dönmez GÇ, Aksu Z, Öztürk A, Kutsal T. Process Biochem. 1999;34(9):885-92. DOI: 10.1016/S0032-9592(99)00005-9.

[13] Kłos A. Ecol Chem Eng S. 2018;25(2):201-16. DOI: 10.1515/eces-2018-0013.

[14] Mehta SK, Gaur JP. Crit Rev Biotechnol. 2005;25(3):113-52. DOI: 10.1080/07388550500248571.

[15] Ramanan R, Kannan K, Deshkar A, Yadav R, Chakrabarti T. Bioresour Technol. 2010;101(8):2616-22. DOI: 10.1016/j.biortech.2009.10.061.

[16] Pankiewicz R, Łęska B, Messyasz B, Fabrowska J, Sołoducha M, Pikosz M. Algal Res. 2016;19:348-54. DOI: 10.1016/j.algal.2016.02.025.

[17] Mansour SA. Thermochim Acta. 1994;233(2):243-56. DOI: 10.1016/0040-6031(94)85118-2.

[18] Van der Velde RY, Brouwers JR, Geusens PP, Lems WF, van den Bergh JP. Food Nutr Res. 2014;58(1):21796. DOI: 10.3402/fnr.v58.21796 .

[19] López-Pérez O, Picon A, Nuñez M. Food Res Int. 2017;99:1002-10. DOI: 10.1016/j.foodres.2016.12.013.

[20] Jeong GT, Park DH. Korean J Chem Eng. 2015;32(12):2463-7. DOI: 10.1007/s11814-015-0083-1.

[21] Vilar VJ, Botelho CM, Boaventura RA. Water Res. 2007;41(7):1569-79. DOI: 10.1016/j.watres.2006.12.031.

[22] Holt AS, Jacobs EE. Plant Physiol. 1955;30(6):553-9. DOI: 10.1104/pp.30.6.553

[23] Plaza M, Santoyo S, Jaime L, Reina GG, Herrero M, Señoráns FJ, et al. J Pharmaceut Biomed. 2010;51(2):450-5. DOI: 10.1016/j.jpba.2009.03.016. 